BUDGETING : Journal of Business, Management and Accounting

Volume 1, Nomor 1, Desember 2019

e-ISSN: 2715-2480

p-ISSN: 2715-1913

DOI : https://doi.org/10.31539/budgeting.v1il.777

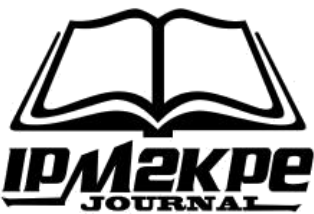

\title{
ANALISIS E-SERVICE DAN KEPERCAYAAN KONSUMEN TERHADAP KEPUASAN KONSUMEN PENGGUNA WEBSITE
}

\author{
Tegar Maulidi Putra1, Asep M. Ramdan', Faizal Mulia ${ }^{3}$ \\ Universitas Muhammadiyah Sukabumi ${ }^{1,2,3}$ \\ tegarmputra27@gmail.com ${ }^{1}$
}

\begin{abstract}
ABSTRAK
Tujuan dalam penelitian ini yaitu untuk mengetahui pengaruh e-service quality dan kepercayaan konsumen terhadap kepuasam konsumen. Penggunaan metode dalam penelitian ini adalah menggunakan jenis sampling termasuk kedalam sampel random sampling dan dengan melakukan penyebaran kuesioner sebanyak 96 kepada konsumen . Teknik analisis yang digunakan adalah teknik analisis linear berganda, dan untuk pengujian hipotesis adalah uji statistik secara parsial (uji t) dan uji secara simultan (uji f). Hasil penelitian uji t menunjukkan bahwa e-service quality (X1) berpengaruh signifikan terhadap kepuasan konsumen, kepercayaan konsumen (X2) berpengaruh signifikan terhadap kepuasan konsumen. Berdasarkan uji $\mathrm{F}$ nilai probabilitas sig $0,000<$ 0,10 yang berarti bahwa secara bersama-sama e-service quality (X1) dan kepercayaan konsumen (X2) berpengaruh signifikan terhadap kepuasan konsumen (Y). Simpulan, secara bersama-sama e-service quality dan kepercayaan konsumen berpengaruh signifikan terhadap kepuasan konsumen
\end{abstract}

Kata Kunci : E-Service Quality, Kepercayaan Konsumen, Kepuasan Konsumen.

\begin{abstract}
The purpose of this study is to determine the effect of e-service quality and consumer confidence on customer satisfaction. The use of the method in this study is to use a type of sampling included in the sample random sampling and by distributing questionnaires as many as 96 to consumers. The analysis technique used is multiple linear analysis techniques, and for hypothesis testing is a statistical test partial (t test) and simultaneous testing ( $f$ test). T test results show that e-service quality (XI) has a significant effect on customer satisfaction, consumer confidence (X2) has a significant effect on customer satisfaction. Based on the F test the probability value sig 0,000 $<0.10$ which means that together e-service quality (X1) and consumer confidence (X2) significantly influence consumer satisfaction $(Y)$. Conclusion, together e-service quality and consumer trust significantly influence consumer satisfaction
\end{abstract}

Keywords: E-Service Quality, Consumer Trust, Consumer Satisfaction. 


\section{PENDAHULUAN}

Menurut Arifin (2011) menyatakan bahwa variabel kepercayaan, fasilitas dan kualitas pelayanan secara simultan berpengaruh positif dan signifikan terhadap kepuasan konsumen. ditunjukan dari nilai $\mathrm{F}$ hitung $>\mathrm{F}$ tabel $(2,82)$. Kemudian menurut Jonathan (2013) bahwa variabel "e-service quality pada website memiliki pengaruh yang signifikan terhadap variabel customer satisfaction.

Menurut Perwira et al (2016) bahwa variabel e-service quality berpengaruh signifikan terhadap variabel kepuasan pelanggan. Sedangkan menurut Prakoso (2017) menyatakan bahwa, ada pengaruh kepercayaan, kualitas pelayanan, harga berpengaruh signifikan terhadap kepuasan konsumen. Sementara, menurut Indriyani dan Helling (2018) menyatakan bahwa variabel hubungan kualitas website, kepercayaan, promosi dan harga secara serentak berpengaruh signifikan terhadap kepuasan pelanggan

Berdasarkan hasil penelitian terdahulu, maka terdapat pengaruh yang siginifikan antara e-service quality dan kepercayaan konsumen terhadap kepuasan konsumen, namun dalam penelitian ini memfokuskan pada kepuasan pelanggan PT. Liza Christina Garment Industry Kabupaten Sukabumi melalui e-service quality, sehingga dapat mempermudah konsumen dalam melihat produk yang ditawarkan perusahaan dan juga meningkatkan kepercayaan konsumen untuk bertransaksi secara online. Dengan semikian perusahaan harus benar-benar memberikan pelayanan yang prima dan meningkatkan kepercayaan konsumen demi tercapainya kepuasan konsumen dan dapat memberikan kontribusi akan tercapainya suatu keinginan cita-cita perusahaan dalam meningkatkan kepuasan konsumen pada pembelanjaan online pada situs yang berbasis website.

\section{KAJIAN TEORI}

\section{E-Service Quality}

Menurut Chase, Jacbs, \& Aquilano (Prakoso 2017, Jonathan, 2013) E-Sevice Quality merupakan versi baru dari Service Quality (ServiQual), E-Service Quality di buat dan dikembangkan untuk mengevaluasi suatu pelayanan dalam dunia internet $(E-$ Commerce) salah satunya dalam situs website. "E-Service Quality didefenisikan sebagi perluasan dari kemampuan suatu situs untuk memfasilitasi kegiatan belanja, pembelian dan distribusi secara efektif dan efisien" 
Berdasarkan Zeithmal \& Parasuraman (Perwira et al, 2016), Adapun dimensidimensi dari E-Service Quality adalah sebagai berikut :

1. Efesiensi : Suatu fungsi yang digunakan untuk memudahkan pelanggan untuk menggunakan, mudah untuk melakukan pencarian, kecepatan dalam mengakses sehingga lebih efisien.

2. Fleksibilitas : Suatu fungsi yang digunakan dalam melakukan pembayaran ataupun kemudahan dalam bertransaksi untuk digunakan pelanggan.

3. System Avaiability :Suatu fungsi yang digunakan apakah pembayaran atau informasi yang diberikan relevan bagi para pelanggan atau tidak.

4. Privasi : Suatu fungsi yang digunakan dalam memberikan keamanan data pribadi, keamanan berteransaksi, ataupun jaminan yang diberikan.

5. Daya Tanggap : Suatu fungsi yang digunakan untuk memberikan kemudahan bagi para pelanggan untuk mendapatkan bantuan apabila memiliki permasalahan ataupun pertanyaan.

6. Compensation : Suatu fungsi apakah penggunaan fitur jaminan dapat digunakan dengan benar dan tepat.

7. Contact: Suatu fungsi yang digunakan untuk para pelanggan dalam menghubungi customer service yang telah disediakan.

Menurut Jonathan (2013) dalam jurnal penelitian nya yang berjudul Analisis Pengaruh E-Service Quality terhadap Customer Satisfaction yang berdampak pada Customer Loyalti PT. Bayu Buana Travel Tbk", Berdasarkan ujihipotesis, diperoleh bahwa hasil dari hipotesis 1 di terima, bahwa variabel "e-service quality pada website bayubuanatravel.com memiliki pengaruh yang signifikan terhadap variabel customer satisaction.

\section{Kepercayaan Konsumen}

Kepercayaan menjadi faktor penting yang harus diperhatikan,karena dalam berbelanja online konsumen telah memberikan kepercayaan atau harapan mereka terhadap apa yang mereka inginkan dan di percayai kepada produk yang dijual oleh perusahaan, oleh sebab itu perusahaan harus bisa memberikan jaminan keamanan ketika akan melakukan transaksi. 
Menurut Robbin dan Judge (Anwar et al., 2018). Kepercayaan Konsumen ialah harapan positif, faktor atau kunci mempengaruhi kepercayaan ada tiga dimensi, yaitu :

1. Integritas (Integrity). Integritas adalah sifat-sifat yang jujur dan bermoral. Kejujuran adalah unsur yang menentukan dalam berkomunikasi. Kejujuran tidak saja menjadikan komunikasi menjadi efektif, tetapi juga mampu menciptakan pengertian dan pemahaman yang baik antara komunikasi dan komunikator. Penyampaian informasi dengan jujur dapat menghindari dari penipuan dan hal yang tidak dinginkan lainnya.

2. Kompotensi (Competence). Kompetensi adalah sifat, pengetahuan, dan pribadi seseorang yang relevan dalam menjalankan tugasnya secara efektif. Kompotensi terdiri atas kompotensi generik dan kompotensi spesifik. Kompotensi generik ialah yang bersifat umum yang harus dimiliki setiap karyawan. Kompotensi spesifik ialah khusus untuk mengerjakan pekerajan khusus dalam bidangnya.

3. Konsisten (Concistency). Konsisten adalah sifat yang teguh dan kokoh pada pendiriannya, meskipun berbagai cobaan menghadang. Seseorang yang konsisten dapat dinilai dari tingkah lakunya, tidak mudah berubah-ubah prilakunya (pikiran, perbuatan dan sikapnya), setiap ucapannya dapat dipercaya, dan sama antara ucapan dan perbuatannya. Tidak konsisten antara ucapan dan perbuatan nya menjadi faktor yang dapat mengurangi kepercayaan.

Menurut Prakoso (2017) dalam penelitian nya menyatakan bahwa, "ada pengaruh kepercayaan, kualitas pelayanan, Harga berpengaruh signifikan terhadap kepuasan konsumen".

\section{Kepuasan Konsumen}

Pengukuran Kepuasan Kotler (Arifin, 2011). Kepuasan dapat diukur dengan beberapa cara, kepuasan dapat diukur dengan menanyakan secara langsung kepuasan konsumen dengan menggunakan skala, responden dapat dimnta untuk memberikan peringkat seberapa besar harapan terhadap atribut tertentu dan seberapa besar yang dialaminya, metode lain dengan meminta responden membuat daftar masalah yang dihadapi dan membuat daftar yang disarankan untuk perbaikan. Menurut Indriyani dan Helling (2018) menyatakan bahwa variabel hubungan Kualitas website, kepercayaan, 
promosi dan harga secara serentak berpengaruh signifikan terhadap kepuasan pelanggan".

\section{METODE PENELITIAN}

Penelitian ini dilaksanakan di PT. Liza Christina Garment Industry Kabupaten Sukabumi. Menggunakan pendekatan Manajemen pemasaran, yang khusus nya membahas E-Service Quality, Kepercayaan Konsumen dan Kepercayaan Konsumen. Populasi dalam penelitian ini adalah konsumen pengguna website PT. Liza Christina Garment Industry Kabupaten Sukabumi. Metode yang digunakan pada penelitian ini adalah menggunakan menggunakan jenis probabilitas sampling yaitu simple random sampling dengan melakukan penyebaran kuesiner sebanyak 96 kepada konsumen pengguna Website pada Produk PT. Liza Christina Garment Industry. Teknik analisis yang digunakan adalah teknik analisi Regresi berganda, termasuk uji koefisien Determinasi, koefisien Korelasi Ganda, Uji Secara Simultan (Uji F), dan Uji Secara Parsial (Uji T).

\section{HASIL PENELITIAN}

\section{Koefisien Korelasi Ganda (R)}

Tabel 1

Hasil Koefisien Korelasi Ganda

Model Summary

\begin{tabular}{|ll|l|ll|l|}
\hline Model $\quad \mathrm{R}$ & R Square & $\begin{array}{l}\text { Adjusted } \\
\text { Square }\end{array}$ & $\begin{array}{l}\text { Std. Error of the } \\
\text { Estimate }\end{array}$ \\
\hline 1 & $.498^{\mathrm{a}}$ & .248 & .232 & 2.358 \\
\hline a. & $\begin{array}{l}\text { Predictors: (Constant), KEPERCAYAAN } \\
\text { KONSUMEN, E- }\end{array}$ \\
& SERVICE QUALITY
\end{tabular}

Sumber: Data Primer (Kuesioner), 2019

Berdasarkan tabel 1 diatas diperoleh angka $\mathrm{R}$ sebesar 0,498 berada pada kategori $0,40-0,599$. Hal ini menunjukan bahwa terjadinya hubungan yang sedang antara $e$ service quality dan kepercayaan konsumen dengan kepuasan konsumen. 


\section{Koefisien Determinasi $\left(\mathbf{R}^{2}\right)$}

Tabel 2

Hasil Koeisien Determinasi

Model Summary

\begin{tabular}{|ll|l|ll|l|}
\hline Model & $\mathrm{R}$ & R Square & $\begin{array}{l}\text { Adjusted } \\
\text { Square }\end{array}$ & $\mathrm{R}$ & $\begin{array}{l}\text { Std. Error of the } \\
\text { Estimate }\end{array}$ \\
\hline 1 & $.498^{\mathrm{a}}$ & .248 & .232 & 2.358 \\
\hline b. & $\begin{array}{l}\text { Predictors: (Constant), KEPERCAYAAN } \\
\text { KERVICE QUALITY KONSUMEN, E- }\end{array}$
\end{tabular}

\section{Sumber: Data Primer (Kuesioner), 2019}

Hasil tabel 2 diatas model summary menyatakan besarnya adjusted $\mathrm{R}^{2}$ sebesar 0,248; hal ini berarti 24,8\% variasi kepuasan konsumen dapat dijelaskan oleh variasi dari dua variabel independen yaitu e-service quality dan kepercayaan konsumen sedangkan sisanya $24,8 \%(100 \%-24,8 \%=75,2 \%)$ dari faktor yang tidak diteliti.

\section{Hasil Analisis Regresi Linear Berganda}

Tabel 3

Hasil Regresi Linear Berganda

\begin{tabular}{|c|c|c|c|c|c|c|}
\hline \multicolumn{7}{|c|}{ Coefficients $^{\mathrm{a}}$} \\
\hline \multirow{2}{*}{\multicolumn{2}{|c|}{ Model }} & \multicolumn{2}{|c|}{$\begin{array}{l}\text { Unstandardized } \\
\text { Coefficients }\end{array}$} & \multirow{2}{*}{$\begin{array}{l}\text { Standardized } \\
\text { Coefficients } \\
\text { Beta }\end{array}$} & \multirow[b]{2}{*}{$\mathrm{t}$} & \multirow[b]{2}{*}{ Sig. } \\
\hline & & $\mathrm{B}$ & Std. Error & & & \\
\hline \multirow[t]{3}{*}{1} & (Constant) & 8.463 & 1.813 & & 4.668 & .000 \\
\hline & E-SERVICE QUALITY & .051 & .061 & .112 & .833 & .407 \\
\hline & $\begin{array}{l}\text { KEPERCAYAAN } \\
\text { KONSUMEN }\end{array}$ & .379 & .124 & .409 & 3.047 & .003 \\
\hline
\end{tabular}

a. Dependent Variable: KEPUASAN KONSUMEN

Sumber: Data Primer (Kuesioner), 2019

Dari output uji regresi linear berganda diatas, maka dapat diperoleh persamaan sebagai berikut ini:

$$
\mathrm{Y}=8.463+0,051 \mathrm{X}_{1}+1.379 \mathrm{X}_{2}
$$




\section{Uji Signifikasi Secara Simultan (Uji F)}

\begin{tabular}{|c|c|c|c|c|c|c|}
\hline \multicolumn{7}{|c|}{$\begin{array}{c}\text { Tabel } 4 \\
\text { Hasil Uji F }^{\text {. }} \\
\text { ANOVA }^{\text {aNO }}\end{array}$} \\
\hline Model & & Sum of Squares & df & Mean Square & $\mathrm{F}$ & Sig. \\
\hline \multirow[t]{3}{*}{1} & Regression & 170.481 & 2 & 85.240 & 15.336 & $.000^{\mathrm{b}}$ \\
\hline & Residual & 516.926 & 93 & 5.558 & & \\
\hline & Total & 687.406 & 95 & & & \\
\hline
\end{tabular}

a. Dependent Variable: KEPUASAN KONSUMEN

b. Predictors: (Constant), KEPERCAYAAN KONSUMEN, E-SERVICE QUALITY

Sumber: Data Primer (Kuesioner), 2019

Hasil tabel 4 di atas, hasil uji $\mathrm{F}$ hitung variabel $\mathrm{X}_{1}$ (E-Service Quality), $\mathrm{X}_{2}$ (Kepercayaan Konsumen) dan Y (Kepuasan Konsumen) adalah sebesar 15.336. maka dapat diperoleh nilai sig. $0,000<0,10$; nilai $F_{\text {hitung }} 15.336>F_{\text {tabel }}$ 2.36. Artinya bahwa e- service quality dan kepercayaan konsumen berpengaruh signifikan terhadap kepuasan konsumen.

\section{Uji Signifikasi Secara Parsial (Uji T)}

\begin{tabular}{|c|c|c|c|c|c|c|}
\hline \multicolumn{7}{|c|}{$\begin{array}{c}\text { Tabel } 5 \\
\text { Hasil Uji T } \\
\text { Coefficients }^{\mathrm{a}}\end{array}$} \\
\hline \multirow{2}{*}{\multicolumn{2}{|c|}{ Model }} & \multicolumn{2}{|c|}{$\begin{array}{l}\text { Unstandardized } \\
\text { Coefficients }\end{array}$} & \multirow{2}{*}{$\begin{array}{l}\text { Standardized } \\
\text { Coefficients } \\
\text { Beta }\end{array}$} & \multirow[b]{2}{*}{$\mathrm{t}$} & \multirow[b]{2}{*}{ Sig. } \\
\hline & & $\mathrm{B}$ & Std. Error & & & \\
\hline \multirow[t]{3}{*}{1} & (Constant) & 8.463 & 1.813 & & 4.668 & .000 \\
\hline & E-SERVICE QUALITY & .051 & .061 & .112 & .833 & .407 \\
\hline & $\begin{array}{l}\text { KEPERCAYAAN } \\
\text { KONSUMEN }\end{array}$ & .379 & .124 & .409 & 3.047 & .003 \\
\hline
\end{tabular}

a. Dependent Variable: KEPUASAN KONSUMEN

\section{Sumber: Data Primer(Kuesioner), 2019}

Berdasarkan table 5 di atlas, hail unit hypothesis unit t yang dilakukan adapt dilate Bahia variable e-service quality inlay sig. $0,000>0,10$; inlay $\mathrm{t}_{\text {hing }} 0.833<\mathrm{t}_{\mathrm{able}}$ 1.66140, actinia e-service quality tidak mempunyai pengaruh signifikan secara partial. Variable kepercayaan konsumen inlay sig. $0,000<0,10$; inlay $\mathrm{T}_{\text {hing }} 3.047>\mathrm{t}_{\text {able }}$ 1.66140, actinia kepercayaan konsumen berpengaruh positif dan signifikan secara parsial terhadap kepuasan konsumen. 


\section{PEMBAHASAN}

E-service quality berpengaruh positif dan signifikan terhadap kepuasan konsumen (Y) secara parsial. Menunjukan bahwa E-Service Quality pada industri cafe memberikan nilai positif dalam mempengaruhi Kepuasan Konsumen pada pegguna Website. Hal ini sejalan dengan hasil penelitian Jonathan (2013 bahwa variabel " $e$ service quality pada website memiliki pengaruh yang signifikan terhadap variabel customer satisfaction. Begitu juga menurut Perwira et al (2016) bahwa variabel $e$ service quality berpengaruh signifikan terhadap variabel kepuasan pelanggan.

Kepercayaan Konsumen berpengaruh positif dan signifikan terhadap Kepuasan Konsumen (Y) secara parsial, menunjukan bahwa Kepercayaan Konsumen pengguna website pada produk PT. Liza Christina Garment Industry memberikan nilai positif dalam mempengaruhi Kepuasan Konsumen pengguna website, hal ini sejalan dengan hasil penelitian Sativa dan Astuti menyatakan bahwa e-trust mempunyai pengaruh tinggi terhadap e-satisfaction konsumen situs Tokpedia. Kemudian hasil penelitian Prakoso (2017) menyatakan bahwa, ada pengaruh kepercayaan, kualitas pelayanan, harga berpengaruh signifikan terhadap kepuasan konsumen

E-Service Quality dan Kepercayaan Konsumen berpengaruh positif dan signifikan terhadap Kepuasan Konsumen (Y) secara simultan. Hal ini dibuktikan dari hasil pengujian uji $\mathrm{F}$ menunjukan nilai sig. $0,000<0,10$; nilai $\mathrm{F}_{\text {hitung }} 37.661>\mathrm{F}_{\text {tabel }} 2.36$, maka dapat disimpulkan bahwa $\mathrm{H}_{\mathrm{a}}$ diterima dan $\mathrm{H}_{0}$ ditolak. Maka menunjukan Bahia $E$ Service Quality dan Kepercayaan Kinsumen berpengaruh signifikan secara bersamasama (simultan) terhadap Kepuasan Konsumen pengguna Website pada produk PT. Liza Christina Garment Industry Kabupaten Sukabumi. Menurut Indriyani dan Helling (2018) menyatakan bahwa variabel hubungan kualitas website, kepercayaan, promosi dan harga secara serentak berpengaruh signifikan terhadap kepuasan pelanggan

\section{SIMPULAN}

Secara keseluruhan E-Service Quality, Kepercayaan Konsumen, dan Kepuasan Konsumen pengguna website pada produk PT. Liza Christina Garment Industry Kabupaten Sukabumi masuk dalam ketegori tinggi yang diartikan perusahaan sudah baik dalam menciptakan kualitas pelayanan pada webiste dalam Kepuasan Konsumen. 


\section{DAFTAR PUSTAKA}

Anwar, R. N., \& Aprillia, R. (2018). Pengaruh Kepercayaan Dan Media Sosial Terhadap Keputusan Pembelian Konsumen E-Commerce Fashion Muslim Hijup Di Jakarta. Jurnal Manajemen Bisnis Krisnadwipayana, 6(1)

Arifin, S. (2011). Pengaruh Kepercayaan, Fasilitas Dan Kualitas Pelayanan Terhadap Kepuasan Konsumen Pada Hotel Jepara Indah. Jurnal Dinamika Ekonomi 68 \& Bisnis, 8(2)

Indriyani, F., Lydia, \& Helling, S. (2018). Analisis Pengaruh Kualitas Website , Kepercayaan, Promosi Dan Harga Terhadap Kepuasan Pelanggan Tokopedia. Jurnal Riset Manajemen, 5(1)

Jonathan, H. (2013). Analisis Pengaruh E-Service Quality. Journal The Winners, 14(2)

Perwira, B. T., Yulianto, E., \& Kumadji, S. (2016). Pengaruh E-Service Quality Dan Perceived Value Terhadap Kepuasaan Pelanggan Dan Loyalitas Pelanggan. Jurnal Administrasi Bisnis (Jab), 38(2)

Prakoso, A. A. (2017). Analisis Pengaruh Kepercayaan, Kualitas Pelayanan, Dan Harga Terhadap Kepuasan Pelanggan Serta Dampak Pada Loyalitas. Manajemen. 